\title{
EFFECTS OF RIBOFLAVIN DEFICIENCY ON THE LIPIDS OF RAT LIVER
}

\author{
Misako TANIGUCHI $^{1}$ and Motoomi NAKAMURA ${ }^{2}$ \\ ${ }^{1}$ Division of Food and Nutrition, Nakamura Gakuen College, Nishiku, Fukuoka 814 \\ ${ }^{2}$ School of Medicine, Kyushu University, Higashiku, Fukuoka 813
}

(Received July 1, 1975)

\begin{abstract}
Summary Newly weaned male rats were maintained on a riboflavinfree diet for 5 weeks, and a study was made on the effect of the deficiency upon liver lipids. The content of glyceride in the livers varied among the deficient rats. High contents of glyceride were demonstrated in one-third of the deficient rats, whereas the similar level as that of control was shown in the remaining deficient rats. Contents of phospholipids and relative amounts of individual phospholipids were not altered significantly by the deficiency.

Riboflavin deficiency exerted effects on fatty acid components of liver lipids. The composition of fatty acids of triglycerides varied in the deficient rats depending on the content of glycerides. However, trends of increase in linoleic acid and decrease in palmitic acid towards fatty liver were observed in the deficiency in comparison with the control. On the other hand, the changes in phospholipid fatty acids were similar in all deficient rats, and the increase in linoleic acid and the decrease in arachidonic acid were brought about by the deficiency compared with controls, respectively.

In liver homogenates, the incorporation of ${ }^{14} \mathrm{C}$-palmitate into triglycerides was higher in the deficient rats irrespective of the presence or absence of fluoride, but incorporation into phospholipids was slightly lower in the deficient rats than in control animals.
\end{abstract}

Some of the symptoms induced by the deficiency of riboflavin are known to be similar to those which are caused by the deficiency of essential fatty acids. In deficiency of essential fatty acids, enlargement of mitochondria and uncoupling of oxidative phosphorylation were observed by WILSON and LEDUC (1), and they postulated that the lack of ATP might activate a negative feedback mechanism, resulting in compensatory increases in the size of the mitochondria. Appearance of gigantic mitochondria was reported in deficiency of riboflavin in mice (2-4)

1 谷口巴佐子, ${ }^{2}$ 中村元臣 
or rats (5). On the other hand, varying results have been reported on oxidative phosphorylation in riboflavin deficiency. BURCH et al. reported that liver mitochondria of riboflavin-deficient rats declined in the respiratory rate and deteriorated in uncoupling of oxidative phosphorylation (6). On the other hand, no defect in oxidative phosphorylation was observed with liver mitochondria of mice (4) or rats (7) by the riboflavin deficiency. In the latter studies, mitochondria were prepared in the presence of EDTA, which is known to protect against the effects of aging, so that impaired effects on the uncoupling by the riboflavin deficiency could be masked. Possibly the uncoupling might be brought about by liberated fatty acids during the preparation of mitochondria, an effect which would be reversible by addition of serum albumin (4). Concentrations of ATP in livers of riboflavin deficient rats were shown to be decreased to less than half of control values (8), and this could be one of the causes for enlargement of mitochondria. However, the change in the mechanism of energy production alone might not be the only factor invoked to explain the change in mitochondrial structure. TANDLER et al. postulated that the alteration in conformation of phospholipids could affect the integrity of mitochondrial structure (3).

In this paper a study was made on the effects of riboflavin deficiency on liver lipids. Incorporation of ${ }^{14} \mathrm{C}$-palmitate into phospholipids and glycerides was also studied, and related to the occurrence of fatty liver in riboflavin deficiency.

\section{EXPERIMENTAL}

\section{Riboflavin deficient diet and maintenance of animals}

Twenty male rats of Wistar King strain newly weaned (body weight, $32 \pm 2 \mathrm{~g}$ ) were maintained on a riboflavin-deficient diet whose composition was essentially the same as reported by TANDLER et al. (2) and shown in Tables 1 and 2. For the control, 10 rats were maintained on the diet to which riboflavin had been added in the amount of $40 \mathrm{mg} / \mathrm{kg}$ of the deficient diet. Each rat was placed in a

Table 1. Composition of diet.

\begin{tabular}{lc}
\hline & $\%$ \\
\hline Sucrose & 58.15 \\
Vitamin free casein $^{\text {Salts }}{ }^{\mathrm{a}}$ & 28.1 \\
Vitamin mixture in casein $^{\mathrm{b}}$ & 3.1 \\
Crisco & 0.5 \\
Choline chloride & 10.0 \\
\hline
\end{tabular}

a McCollum's salt mixture No. 185.

b Inositol, $200 \mathrm{mg}$; thiamine hydrochloride, $10 \mathrm{mg}$; pyridoxine hydrochloride, $10 \mathrm{mg}$; niacin, $40 \mathrm{mg}$; calcium pantothenate, $40 \mathrm{mg}$; menadione, $6 \mathrm{mg}$; biotin, $0.06 \mathrm{mg}$; tocopherol succinate, $20 \mathrm{mg}$; folic acid, $5 \mathrm{mg}$; ascorbic acid, $20 \mathrm{mg}$; vitamin A acetate, $2.5 \times 10^{3} \mathrm{IU}$; vitamin $\mathrm{D}_{2}, 0.25 \times 10^{3} \mathrm{IU}$; vitamin free casein to $1 \mathrm{~g}$. 
Table 2. Composition of fatty acid in crisco.

\begin{tabular}{crr}
\hline Fatty acid & \multicolumn{1}{c}{ I } & \multicolumn{1}{c}{ II } \\
\hline $12: 0^{\mathrm{a}}$ & 0.3 & 0.3 \\
$14: 0$ & 0.5 & 0.4 \\
$16: 0$ & 21.2 & 19.2 \\
$18: 0$ & 8.1 & 9.7 \\
$18: 1$ & 34.9 & 36.5 \\
$18: 2$ & 32.6 & 31.7 \\
\hline
\end{tabular}

Values are weight percent of fatty acid.

I and II: Sample number of crisco of $192 \mathrm{c} 21$ and $76 \mathrm{c} 63$, respectively.

a Number of carbon atoms: number of double bonds.

separate cage and allowed to eat the diet ad libitum. The animals were weighed at three day intervals. The entire experiment was repeated three times.

\section{Preparation of lipids}

In each experiment, one control and two or three deficient rats were sacrificed by decaptation. The livers were removed immediately and immersed into a cold $0.25 \mathrm{M}$ sucrose solution. A portion of liver ( 1 to $2 \mathrm{~g}$ ) was weighed and lipids were extracted with chloroform/methanol $=2 / 1(\mathrm{v} / \mathrm{v})$; according to the method of Folch et al. (9). The extracted lipid solution was washed with $0.03 \% \mathrm{MgCl}_{2}$ aqueous solution and the chloroform layer was washed three times with a mixed solution of chloroform/methanol $/ 0.036 \% \mathrm{MgCl}_{2}=3 / 48 / 47(\mathrm{v} / \mathrm{v} / \mathrm{v})$. The lower chloroform layer after washing was evaporated under nitrogen gas, and lipids were dissolved in 5 to $10 \mathrm{ml}$ of chloroform containing $0.5 \%$ methanol. Small pieces of $\mathrm{Na}_{2} \mathrm{SO}_{4}$ were added to the solution to remove water, and the lipids was kept at $-15^{\circ} \mathrm{C}$ until further analysis was carried out.

\section{Analysis of lipids}

To determine individual phospholipids, they were separated by thin-layer chromatography with silica gel $\mathrm{H}$ (E. Merck), using the solvent of chloroform/ methanol/water $=65 / 25 / 4(\mathrm{v} / \mathrm{v} / \mathrm{v})$. The location of each phospholipid was identified by iodine vapor, and each area was scraped and transferred into a microkjeldahl flask. Each phospholipid fraction was digested with $72 \%$ perchloric acid without separating the silica gel, and then phosphorus was determined by the method of CoLLINS and WHEELDEN (10).

For the determination of glycerol in glycerides, lipids were separated into glycerides and phospholipids by florisil column chromatography (11). The sample of lipids was dissolved in petroleum ether/ethyl ether $=95 / 5(\mathrm{v} / \mathrm{v})$, and applied on the column of florisil $(200 \times 4 \mathrm{~mm}(i . d)$.$) , and glycerides were eluted by$ the solution of chloroform/acetone/water $=99 / 99 / 2(\mathrm{v} / \mathrm{v} / \mathrm{v})$. The effluents were hydrolyzed with alcoholic-KOH. Taking an aliquot of the saponified solution, glycerol was oxidized with periodate and determined by chromotropic acid method 
as described by LAMBERT and NeISH (12).

\section{Analysis of fatty acid}

A portion of lipids containing less than $10 \mathrm{mg}$ of fatty acid was saponified and fatty acids were methylated with $\mathrm{BF}_{3}$-methanol mixture (13). Methyl esters were analyzed by gas chromatography, using a Perkin Elmer gas chromatograph (Model 881). Quantitative results with the standard fatty acid mixture (Applied Science Lab.) agreed with the stated data, having a relative error within $5 \%$.

The composition of fatty acids in triglycerides and phospholipids was analyzed respectively, after separation of each fraction by thin-layer chromatography with silica gel H, using a solvent system according to SKIPSKI et al. (14). The plates were sprayed with $0.2 \%$ dichlorofluorescein in ethanol $(\mathrm{w} / \mathrm{v})$ and the areas of the lipids were detected under ultraviolet light. The lipids were eluted from silica gel with $5 \mathrm{ml}$ of a solvent mixture of chloroform/methanol/acetic acid/water = $50 / 39 / 1 / 10(\mathrm{v} / \mathrm{v} / \mathrm{v} / \mathrm{v})$ three times according to FeX (15). The combined eluates were washed with $4 \mathrm{M}$ ammonium hydroxide solution. The chloroform layer was successively washed with a solution of $50 \%$ methanol in water containing $0.5 \%$ $\mathrm{NaCl}(\mathrm{w} / \mathrm{v})$. When fatty acids were analyzed, the lipids were saponified, and the fatty acids were methylated as described above.

\section{Incorporation of ${ }^{14} C$-palmitate into lipids}

The reaction mixture was essentially the same as that described by SMITH and

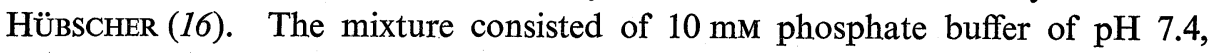
$7.5 \mathrm{~mm}$ ATP, $0.05 \mathrm{~mm}$ CoA, $20 \mathrm{~mm}$ DL- $\alpha$-glycerophosphate, $7.2 \mathrm{mM} \mathrm{MgCl}_{2}$ and $2 \mathrm{~mm}$ glutathione. When fluoride was added, the final concentration was $3.5 \mathrm{~mm}$ $\mathrm{NaF}$. The fatty acids, $0.1 \mu$ mole of ${ }^{14} \mathrm{C}$-palmitate $(0.33 \mu \mathrm{Ci}$; Radiochemical Centre, Amershem, England) and $0.1 \mu$ mole of oleate were added as albumin complexes, which were prepared by incubation of $1 \mu$ mole of each fatty acid with $200 \mathrm{mg}$ of bovine serum albumin fraction V (Armour and Co.) in $2 \mathrm{ml}$ of water at $37^{\circ} \mathrm{C}$ for $10 \mathrm{~min}$, and then treated by a Tominaga Works ultrasonic vibrator (Model UR-150P; 168w, 3.8 Amper) for 5 min.

The livers were homogenized with a cold $0.25 \mathrm{M}$ sucrose solution, and centrifuged at 3,000 rpm for $20 \mathrm{~min}$. Concentration of protein in the supernatant was determined by LowRY's method (17), and an aliquot containing 5 to $6 \mathrm{mg}$ of protein was incubated with the above reaction mixture in a total volume of $2 \mathrm{ml}$ at $37^{\circ} \mathrm{C}$ for $20 \mathrm{~min}$. The reaction was terminated by addition of 20 volumes of chloroform/methanol mixture $(1 / 1=\mathrm{v} / \mathrm{v})$. The residue was extracted with chloroform $/$ methanol $=2 / 1(\mathrm{v} / \mathrm{v})$, and the lipid solutions were combined. The sample of lipids was prepared as described elsewhere in this paper.

The rate of incorporation of ${ }^{14} \mathrm{C}$-palmitate into each lipid fraction was determined after separation of the lipids by thin-layer chromatography according to SKIPSKI et al.(14). The location of each lipid was detected with iodine vapor, 
and the sections were transferred into the vials. The radioactivity was counted by liquid scintillation counter (Hitachi-Horiba LS 500), using $10 \mathrm{ml}$ of scintillator solution containing $4 \mathrm{~g}$ of 2,5-diphenyloxazole and $0.1 \mathrm{~g}$ of 1,4-bis(5-phenyloxazol2-yl) benzene in 1 liter of toluene. All values were calculated as the radioactivity (cpm) recovered in each fraction per $\mathrm{mg}$ of protein incubated.

\section{MATERIALS}

Vitamin-free casein was purchased from Nutritional Biochemicals Corporation and contained $0.5 \mu \mathrm{g}$ of riboflavin per gram, according to the report from the Corporation. Adenosine triphosphate and Coenzyme A were purchased from Boehringer Mannheim, and all other chemicals were analytical grade quality. All solvents were redistilled before use.

\section{RESULTS}

\section{Growth and gain of body weight}

For the first several days, the rats of the riboflavin deficient group gained in body weight at nearly the same rate as the controls, and then decreased in growth rate. After 5 weeks on the deficient diet, rats weighing less than $55 \mathrm{~g}$ were selected as the deficient animals. One-fifth of the deficient group gained more than $55 \mathrm{~g}$, and these animals did not show deficient symptoms, such as dermatitis of the lip and nose, and conjunctivitis. Therefore, these animals were not used as deficient rats.

\section{Occurrence of fatty liver}

After 5 weeks of feeding the diet, the ratio of liver to body weight increased in the deficient rats, but the difference was not significant (Table 3). However, in one-third of the deficient fatty livers were macroscopically observed and the ratio of liver to body weight of these rats increased over $7 \%$. Five of the fatty

Table 3. Effect of riboflavin deficiency on weights of body and liver.

\begin{tabular}{|c|c|c|c|c|c|c|}
\hline \multirow[t]{2}{*}{ Exp. } & \multicolumn{3}{|c|}{ Riboflavin-deficient } & \multicolumn{3}{|c|}{ Control } \\
\hline & Days $^{2}$ & $\begin{array}{c}\text { Body weight } \\
\mathrm{g}\end{array}$ & $\underset{\%}{\text { Liver/Body }}$ & Days $^{a}$ & $\begin{array}{c}\text { Body weight } \\
\text { g }\end{array}$ & $\begin{array}{c}\text { Liver/Body } \\
\%\end{array}$ \\
\hline 1 & $35-40$ & \multicolumn{2}{|c|}{$46.4 \pm 8.8$ (20) $6.4 \pm 1.1$} & $35-40$ & \multicolumn{2}{|c|}{ (10) } \\
\hline 2 & $35-45$ & \multicolumn{2}{|c|}{$47.6 \pm 10.4_{(20)} 6.9 \pm 1.2$} & $30-48$ & \multicolumn{2}{|c|}{ (10) } \\
\hline 3 & $32-42$ & $43.3 \pm 9.8$ & 0) $6.9 \pm 1.3$ & $35-42$ & $198.5 \pm 25.8$ & $5.2 \pm 0.6$ \\
\hline
\end{tabular}

\footnotetext{
a Days of feeding the diets.
}

Values are average \pm S.D., and numbers in parentheses are the animals. 
Table 4. Concentration of glyceride-glycerol and phospholipidphosphorus in liver lipids.

\begin{tabular}{cccc}
\hline & \multicolumn{2}{c}{ Riboflavin-deficient } \\
Group I & Group II & Control \\
$(5)$ & $6.4 \pm 2.1$ & $57.2 \pm 23.1^{*}$ & $6.0 \pm 1.3$ \\
\hline $\begin{array}{c}\text { Glyceride-glycerol } \\
\quad(\mu \text { mole/g. of liver) } \\
\begin{array}{c}\text { Phosphorus in lipids } \\
(\mu \text { mole/g. of liver) }\end{array}\end{array}$ & $32.3 \pm 7.5$ & $43.3 \pm 3.2$ & $36.6 \pm 5.3$ \\
\hline
\end{tabular}

Group I: Deficient but not fatty liver. Group II: Deficient and fatty liver. Numbers in parentheses are the number of rats.

Values are average \pm S.D., and expressed as $\mu$ mole $/ g$ of wet weight of liver.

* expressed significant difference $(p<0.01)$ from group I or control.

livers and five from the rest of deficients were taken for the analysis of the contents of glyceride and phospholipid, and the results were shown in Table 4. The quantities of glycerides were determined as glycerol, and the glycerides in the liver lipids of the deficient but not fatty liver, group I, were similar with those of the controls, whereas the content of glycerides in fatty livers, deficient group II, increased several times above that of controls or the deficient group I. However, the phospholipids determined as phosphorus did not change significantly in all deficient rats.

\section{Phospholipids}

Since there was not much difference in the concentration of phosphorus in phospholipids between the two deficient groups, the analysis of the content of individual phospholipids was determined without dividing deficient animals into two groups. As shown in Table 5, there was found to be a trend of an increase in phosphatidylethanolamine in riboflavin deficiency; however, the change was not statistically significant, compared with the control value.

Table 5. Liver phospholipids.

\begin{tabular}{lcc}
\hline \multicolumn{1}{c}{ Fraction } & $\begin{array}{c}\text { Riboflavin-deficient } \\
(9)\end{array}$ & $\begin{array}{c}\text { Control } \\
(5)\end{array}$ \\
\hline Phosphatidylinositol & $13.0 \pm 2.0 \%$ & $11.8 \pm 2.2 \%$ \\
Phosphatidylcholine & $53.0 \pm 4.4$ & $54.6 \pm 1.3$ \\
Phosphatidylethanolamine & $24.6 \pm 2.3$ & $22.6 \pm 1.2$ \\
Cardiolipin & $6.0 \pm 1.7$ & $6.3 \pm 1.0$ \\
\hline
\end{tabular}

Numbers in parentheses are numbers of rats.

Values are average \pm S.D. of percentage of phosphorus of each phospholipids in liver lipids.

\section{Fatty acid composition}

The composition of fatty acid of total liver lipids differed in the two groups of deficient rats as shown in Table 6. In the deficient group I, 14:0* and 18:2

\footnotetext{
* Number of carbon atoms: number of double bonds.
} 
Table 6. Composition of fatty acids in total liver lipids.

\begin{tabular}{cccr}
\hline $\begin{array}{c}\text { Fatty } \\
\text { acid }\end{array}$ & \multicolumn{2}{c}{ Riboflavin-deficient } \\
& $\begin{array}{c}\text { Group I } \\
(9)\end{array}$ & $\begin{array}{c}\text { Group II } \\
(7)\end{array}$ & \multicolumn{1}{c}{ Control } \\
\hline $14: 0^{\mathrm{a}}$ & $0.47 \pm 0.22^{*}$ & $1.51 \pm 0.52^{*}$ & $0.16 \pm 0.05$ \\
$16: 0$ & $14.37 \pm 1.58$ & $13.63 \pm 0.74$ & $14.41 \pm 0.92$ \\
$16: 1$ & $1.14 \pm 0.35$ & $2.41 \pm 0.27^{*}$ & $1.37 \pm 0.35$ \\
$18: 0$ & $17.76 \pm 1.63$ & $11.51 \pm 1.78^{*}$ & $17.39 \pm 1.37$ \\
$18: 1$ & $12.88 \pm 1.87^{*}$ & $24.32 \pm 2.35^{*}$ & $16.34 \pm 1.15$ \\
$18: 2$ & $15.73 \pm 1.25^{*}$ & $20.40 \pm 2.61^{*}$ & $9.88 \pm 0.96$ \\
$20: 4$ & $23.33 \pm 1.82^{*}$ & $14.46 \pm 3.13^{*}$ & $29.17 \pm 1.33$ \\
$22: 4$ & $2.02 \pm 0.43$ & $1.37 \pm 0.58$ & $1.78 \pm 0.51$ \\
$22: 6$ & $8.38 \pm 1.67$ & $5.05 \pm 1.26^{*}$ & $7.33 \pm 0.37$ \\
\hline
\end{tabular}

Values are means \pm S.D. in weight percent of fatty acid.

a Number of carbon atoms: number of double bonds.

Group I and II are the same as shown in Table 4, and numbers in parentheses indicate the number of rats.

* Significantly different from control $(p<0.01)$.

increased, and 18:1 and 20:4 decreased respectively, compared with the controls. On the other hand, in the deficient group II with fatty livers, 14:0, 16:1, 18:1 and 18:2 increased and 18:0,20:4 and 22:6 decreased respectively, compared with the controls. In both deficient groups, the increase in 14:0 and 18:2 and the decrease in 20:4 were generally observed, whereas the increase in 16:1 and 18: 1 , and the decrease in 18:0 and 22: 6 only appeared in the deficient group II with fatty livers.

Remarkable differences in fatty acid were observed in the lipids of fatty livers, but the diversity was considered due to the high content of triglycerides as shown in Table 4, in which composition of fatty acid was characteristically different from that of phospholipids. In order to elucidate the diverse effects of the deficiency on fatty acid composition, and also to distinguish the effect upon fatty acids between phospholipids and triglycerides, the liver lipids were separated on thin layer chromatography, and fatty acids in each lipid were analyzed. As shown in Table 7, the composition of fatty acids in triglycerides varied in the two deficient groups. On the other hand, fatty acid composition of the phospholipids followed a similar trend; increases in 18:2 and decreases in 20:4 were shown in both groups as for total lipids.

\section{Incorporation of ${ }^{14} \mathrm{C}$-palmitate into lipids}

Incorporation of ${ }^{14} \mathrm{C}$-palmitate was studied with liver homogenates, and the results are shown in Table 8. The rate of incorporation of ${ }^{14} \mathrm{C}$-palmitate into triglycerides was significantly accerelated by the deficiency, whereas only a small decrease of incorporation into phospholipid was observed. In the presence of $\mathrm{NaF}$, which is known to inhibit phosphatidate phosphohydrolase (18), the synthesis 


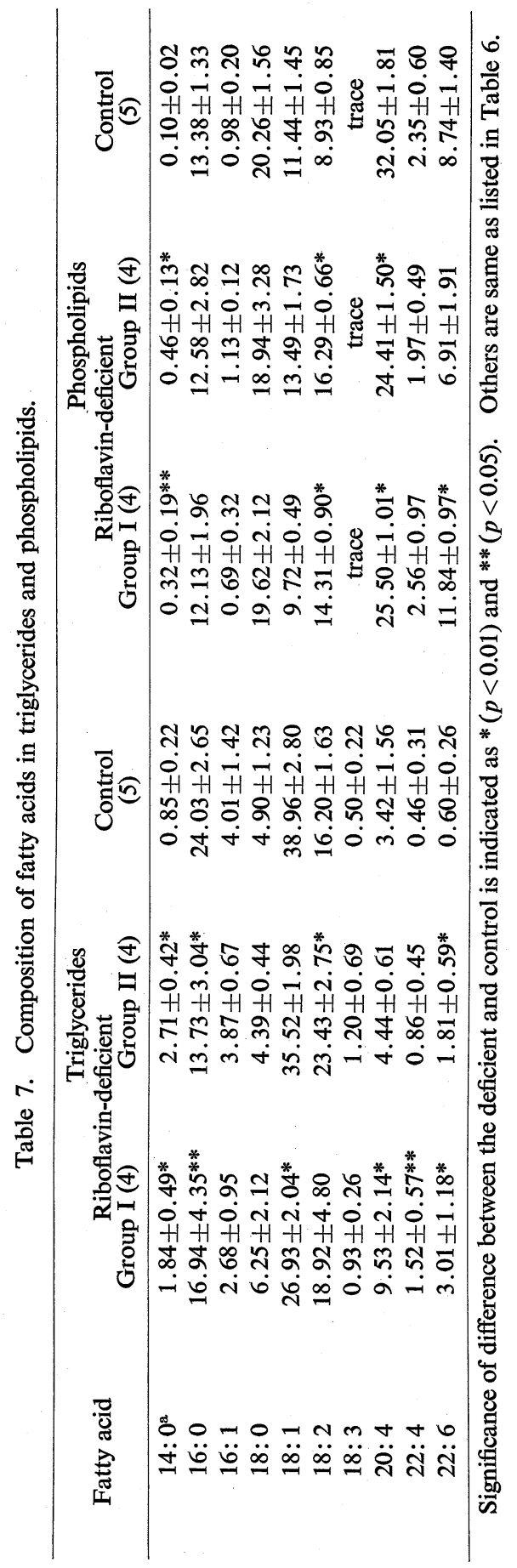


Table 8. Distribution of labelled palmitate incorporation into lipids.

\begin{tabular}{lrrrrrrrrr}
\hline \multicolumn{1}{c}{ Compound } & \multicolumn{3}{c}{ Riboflavin-deficient } & \multicolumn{3}{c}{ Control } \\
\hline & \multicolumn{2}{c}{$\mathrm{NaF}-$} & \multicolumn{1}{c}{$\mathrm{NaF}+$} & \multicolumn{1}{c}{$\mathrm{NaF}-\bar{c}$} & \multicolumn{1}{c}{$\mathrm{NaF}+$} \\
& 2.45 & 32.5 & 2.55 & 32.7 & 2.90 & \multicolumn{1}{c}{ (b) $\%$} & \multicolumn{1}{c}{ (a) } & (b) $\%$ \\
\hline Phospholipids & 2.5 & 2.89 & 48.8 \\
1,2-Diglyceride & 0.96 & 12.8 & 1.43 & 18.3 & 0.65 & 11.0 & 1.38 & 23.3 \\
1,3-Diglyceride & 0.27 & 3.5 & 0.32 & 4.1 & 0.16 & 2.7 & 0.17 & 2.9 \\
Triglyceride & 3.65 & 48.3 & 3.32 & 42.4 & 1.77 & 33.2 & 1.28 & 21.7 \\
Cholesterolester & 0.22 & 2.9 & 0.21 & 2.6 & 0.40 & 3.7 & 0.20 & 3.4 \\
\hline
\end{tabular}

Lipids were extracted from the reaction products from homogenates of two rats, and each compound was separated by thin-layer chromatography.

(a) ${ }^{14} \mathrm{C}$-palmitate incorporated $\mathrm{nmoles} / \mathrm{mg}$ protein $/ 20 \mathrm{~min}$.

(b) Percent of ${ }^{14} \mathrm{C}$-palmitate incorporated into total lipids.

of triglyceride was reduced both in control and deficient liver; however the rate of incorporation into triglyceride was still higher in deficiency than control. The rate of incorporation into phospholipids was not affected by $\mathrm{NaF}$. If whole sequential reactions of phospholipid synthesis was limited by the amount of available diglyceride, decreased incorporation into triglyceride in the presence of $\mathrm{NaF}$ would have followed a similar trend of decreased rate as the incorporation into phospholipids.

\section{DISCUSSION}

Riboflavin deficiency exerted effects upon the composition of fatty acids in liver lipids. However, varied effects were demonstrated in fatty acids of the triglyceride fraction between the deficient groups of normal and fatty liver, that is, the deficient groups of I and II respectively. Successive transformation from control to normal deficiency (I) to deficiency with fatty liver (II) was not observed in relation to the comparison of constituents of fatty acids in triglycerides in the two groups, except for progressive increases in linoleic acid and decreases in palmitic acid towards fatty liver.

The total content of phospholipids and relative amounts of individual phospholipids in the liver were not significantly altered by the deficiency. However, considerable change was found in the constituent fatty acids in phospholipids, and increase in linoleic acid and decrease in arachidonic acid were generally observed in both groups of deficient animals.

Although little is known of the states of lipids in mitochondrial membranes, there have been several reports on the relation of lipids to biological functions in membranes. One of the roles of mitochondrial phospholipids is considered to provide binding sites for cations $(19,20)$, while studies with Saccharomyces cerevisiae indicate that the proportion of polyunsaturated fatty acid in membrane 
lipid affects ejection and uptake of protons $(21,22)$. Alteration of polyunsaturated fatty acids by riboflavin deficiency could affect the permeability of mitochondrial membranes to cations and protons, and would consequently result in morphological changes.

KoyAnagi and Oikawa (23) found that accumulation of linoleic acid and reduction of arachidonic acid were brought by riboflavin deficiency in the rat serum lipids. However, no change in fatty acid content of the liver lipids was reported in their experiments. One of the reasons for the varied results from the present data might be due to the difference in the amount, and the species of oil in the diet. They used $18 \%$ soy bean oil in the total diet, whereas $10 \%$ crisco was added in the present experiment. According to their analysis, soy bean oil consisted of $53 \%$ linoleic acid. In crisco, $33 \%$ linoleic acid was estimated. High quantities of linoleic acid in the diet would raise the content of this acid higher in liver lipids, and would result in a relatively low content of arachidonic acid. The reduction of the latter acid by the deficiency might be delayed or masked by large quantities of linoleic acid in the diet. This may be presumed by the results of fatty acid analysis of liver lipids in the two experiments; in their report, linoleic acid was $38 \%$ and arachidonic acid was $4.9 \%$ in the control lipids, whereas $9.9 \%$ and $29 \%$ were found respectively in the present studies.

In rat tissue, the desaturating sequence of electron transfer in synthesis of unsaturated fatty acids was proposed to include flavoproteins between NADPH or NADH and cytochrome $b_{5}(24)$. Thus the riboflavin deficiency might affect the overall reaction in desaturation and elongation. Though the turnover rates of each acid were not determined in this experiment, intermediates of linoleic acid to arachidonic acid were not detected in significant amounts in deficient liver lipids.

The varied results have been reported on formation of fatty liver by riboflavin deficiency. Some studies $(25,26)$, including this paper, demonstrated fatty livers in riboflavin-deficient rats, while no change was observed by INNAMI et al. (27). As mentioned in the latter paper, the different results might be attributable to the content of fat in the diet: the diets containing more than $10 \%$ fat were fed to rats in the former studies, whereas $5 \%$ fat was used in the latter. Since the metabolism of fatty acid is degraded by riboflavin deficiency, ingestion of large amount of fat might accerelate the disturbance of fat metabolism, and this might relate to formation of fatty liver.

There might be diverse causes for the development of liver steatosis, as follow: i) increase in synthesis of triglycerides in liver, ii) increase in influx of plasma fatty acids to liver and decrease in output of fat to plasma, iii) decrease in oxidation of fat, iv) reduction in synthesis of low density lipoprotein and v) increase in peroxide formation.

The etiology of fatty liver caused by deficiency of riboflavin appears to be similar to the deficiency of essential fatty acids, but somewhat more complex. In 
deficiency of riboflavin, the content of arachidonic acid in liver lipids was decreased as observed in deficiency of essential fatty acids (28). Since arachidonic acid is known as a precursor for prostaglandins, one action of which is to inhibit hormone sensitive lipases in rat adipose tissue (29), the effect of riboflavin deficiency might be anticipated to elevate the level of fatty acids in plasma and to accerelate an influx of fatty acids into liver. In addition, incorporation of ${ }^{14} \mathrm{C}$ palmitate into triglycerides was shown to be accerelated in this paper, and a decrease in oxidation of fatty acids was previously reported in riboflavin deficiency $(6,7)$.

Although the mechanism of initiation of fatty liver is controversial, a number of reports have appeared on the correlation of lipid peroxide formation with occurence of fatty liver in rats, and increase in lipid peroxide was demonstrated in rat liver by riboflavin deficiency (30). Therefore in deficiency of riboflavin, lipid peroxide increase, as well as the metabolic disturbances in lipid mentioned above would contribute to the complexity of factors underlying the fatty liver in cases of riboflavin deficiency.

The authors are grateful to Professor W. C. McMurray, Department of Biochemistry, University of Western Ontario, London, Canada, for his helpful advice and kind reading of our manuscript.

\section{REFERENCES}

1) Wilson, J. W. and Leduc, E. H., J. Cell Biol., 16, 281 (1963).

2) Tandler, B., Erlandson, M. S., and Wynder, E. L., Am. J. Pathol., 52, 69 (1969).

3) Tandler, B., Erlandson, M. S., Smith, A. L., and Wynder, E. L., J. Cell Biol., 41, 477 (1969).

4) McMurray, W. C. and Rogers, L., Can. J. Biochem., 51, 1262 (1973).

5) Nishina, N., Vitamins (in Japanese), 37, 345 (1968).

6) Burch, H. B., Hunter, F. E., Jr., Combs, A. M., and Schutz, B. A., J. Biol. Chem., 235, 1540 (1960).

7) Taniguchi, M., Yamauchi, R., and Nakamura, M., J. Jap. Soc. Food Nutr. (in Japanese), 25, 681 (1972).

8) Burch, H. B., Lowry, O. H., Bradley, M. E., and Max, P. F., Jr., Am. J. Pathol., 219, 409 (1970).

9) Folch, J., Lees, M., and Sloane-Stanley, G. H., J. Biol. Chem., 226, 497 (1959).

10) Collins, F. D. and Wheelden, L. W., Nature, 175, 722 (1955).

11) Blankenhorn, D. H., Rouser, G., and Weimer, T. J., J. Lipid Res., 2, 281 (1961).

12) Lambert, M. and Neish, A. C., Can. J. Res. Sect. B., 28, 83 (1950).

13) Morrison, W. R. and SMith, L. M., J. Lipid Res., 5, 600 (1964).

14) Skipski, V. P., Smolowe, A. F., Sullivan, R. C., and Barclay, M., Biochim. Biophys. Acta, 106, 386 (1965).

15) FeX, G., Biochim. Biophys. Acta, 231, 161 (1971).

16) SMith, M. E. and HÜBSCHER, G., Biochem. J., 101, 308 (1966).

17) Lowry, O. H., Rosebrough, N. J., FARr, A. L., and Randall, R. J., J. Biol. Chem., 193, 265 (1951).

18) Smith, M. E., Sedwick, B., Brindley, D. N., and HüBsCher, G., Eur. J. Biochem., 3, 70 (1967). 
19) SCARPa, A. and Azzone, G. F., Biochim. Biophys. Acta, 173, 78 (1969).

20) JACoBus, W. E. and Brierley, G. P., J. Biol. Chem., 244, 4995 (1969).

21) Haslam, J. M., Spithill, T. W., Linnane, A. W., and Chappell, J. B., Biochem. J., 134, 949 (1973).

22) Haslam, J. M., Cobon, G. S., and Linnane, A. W., Biochem. Soc. Trans., 2, 207 (1974).

23) Koyanagi, T. and Orkawa, K., Vitamins (in Japanese), 31, 185 (1965).

24) Jones, P. D., Holloway, P. W., Peluffo, R. O., and Wakil, S. J., J. Biol. Chem., 244, 744 (1969).

25) TAKEUCHI, T., Vitamins (in Japanese), 36, 181 (1957).

26) YAMADA, T., Nagoya Igaku, 73, 1015 (1957).

27) Innami, S., Nakamura, A., Tezuka, T., and Nagayama, S., Jap. J. Nutr. (in Japanese), 26, 189 (1971).

28) Sinclair, A. J. and Collins, F. D., Biochim. Biophys. Acta, 152, 498 (1968).

29) Bergström, S., Carlson, L. A., and Orö, L., Acta Physiol. Scand., 60, 170 (1964).

30) Yамамото, Y., Vitamins (in Japanese), 31, 260 (1965). 